\title{
DESENHANDO A QUADRA HÍBRIDA NO COTIDIANO DOS BAIRROS
}

DRAWING THE HYBRID BLOCK IN THE DAILY LIFE OF NEIGHBORHOODS

\section{SUASSUNA, MARCO}

Arquiteto, Mestre (Unipê e Unifacisa), E-mail: marcosuassuna@gmail.com

\section{LACERDA JR, LÚCIO}

Graduado em Arquitetura e Urbanismo (Centro Universitário de João Pessoa - Unipê), E-mail: rushio.san@gmail.com

\author{
AIRES, INAIAMA \\ Graduanda em Arquitetura e Urbanismo (Faculdade de Ciências Sociais Aplicadas - Unifacisa),E-mail: inaiama@gmail.com
}

\section{RESUMO}

O artigo reflete sobre os danos que o parcelamento do solo hermético repercute no espaço urbano, derivado de legislações urbanísticas antiquadas que "desenham a quadra fechada" nos bairros. A partir dos lotes murados, dos edifícios isolados e da interferência míope do mercado imobiliário no processo de urbanização, é desencadeada a desertificação das calçadas, a hostilidade aos pedestres e a negação do espaço público. Como contraponto, este artigo apresenta uma proposta "piloto-investigativa" em uma quadra urbana típica do bairro de Mangabeira, em João Pessoa - PB, buscando avaliar comparativamente as relações dos pedestres com as calçadas, os usos e a animação urbana no espaço citadino. É apontada a necessidade da revisão das legislações urbanísticas como pressuposto da qualidade urbana.

PALAVRAS-CHAVE: urbanismo; bairro; quadra híbrida.

\section{ABSTRACT}

This article reflects about the damage caused by the land subdivision and how it reflects on the urban enviroment, based in an old urban legislation which "designs a closed block" in the neighborhoods. From the closed lot and the housin market's short-sighted interference in the urbanization process, it leads to the process of emptying sidewalks, the hostility to the pedestrians and the denial of the public spaces. As a counterpoint, this article introduces a "pilot-investigative" proposition of a typical block present in neighborhoods of Mangabeira, in the city of João Pessoa - PB, aiming to comparatively evaluate the relationships between the pedestrians and the sidewalks, the usages and the urban vivacity in the space of a city. It is pointed out the need to review urban legislation as a prerequisite of urban quality. KEYWORDS: urbanism; neighborhood; hybrid block. 


\section{INTRODUÇÃO}

A dinâmica urbana de diversos bairros das cidades brasileiras vem sendo transformada, sobretudo pela verticalização conduzida sem planejamento e pelo uso habitacional multifamiliar restrito, com evidentes sintomas de um urbanismo que nega o espaço público e não atende às demandas cotidianas dos moradores em termos de provisão de comércios e serviços. Bairros cujas paisagens eram formadas por casas térreas ou de dois pavimentos, foram posteriormente demolidas e transformadas em edifícios de três, quatro ou mais pavimentos a depender do zoneamento da cidade.

Tais mudanças devem-se ao fato da valorização do lote sem regulação do poder público, que inflaciona exageradamente o valor por metro quadrado deste, motivado também, em alguns casos, pela localização de proximidade a importantes equipamentos urbanos, dentre eles praças, supermercados, universidades e centros comerciais, todavia de forma fragmentada no tecido urbano. Neste sentido, pela lógica do setor da construção civil em obter o maior lucro em um lote remembrado e pelo parcelamento do solo hermético derivado da legislação urbanística antiquada (Lei $n^{\circ}$ 6.766-1979) que "desenha a quadra fechada" nos bairros, os edifícios isolados do modelo predominante da verticalização pontual, repercute negativamente no espaço público e na vida dos moradores, fator agravado ainda mais pela influência danosa da dependência do automóvel particular nos deslocamentos intraurbanos.

Esse monofuncionalismo fragmentado não estimula o ato de caminhar, o permanecer e nem as trocas sociais, aspectos essenciais da qualidade urbana na escala do bairro e da cidade. Isso demonstra que a verticalização acompanhada da densidade construtiva devem ser planejadas visando a otimização do solo, mas pensando na polifuncionalidade e vitalidade urbanas. Nesse modelo mercadológico, não são consideradas a paisagem humana, as relações de vizinhança ou a vida ao nível dos olhos, e os térreos das edificações são predominantemente fechados ou separados por muros altos cegos, decorrentes do uso residencial multifamiliar não ser combinado com outros usos no térreo. Em uma situação contrária, esta combinação de usos contribuiria para gerar fachadas ativas e a animação urbana de dia e de noite.

Interessa, portanto, investigar possibilidades de intervenções na escala do bairro, capazes de amenizar os impactos negativos nos espaços públicos gerados pela verticalização míope. Quais estratégias espaciais na quadra urbana podem ser adotadas para gerar maior qualidade de vida? Como conciliar a ação do mercado imobiliário na espacialidade do bairro de forma mais humanizada, com calçadas movimentadas para caminhar, permanecer, se divertir, combinando o uso residencial com o comercial, de serviços e áreas de permanências?

Se as transformações ao longo do tempo na paisagem urbana ocorrem, porque não acontecer de forma planejada, pensando na qualidade de vida cotidiana das pessoas? "Vida, espaço e edifícios, nessa ordem" são as diretrizes colocadas por Jan Gehl (2013) para se desenhar as cidades. Atuar na escala do bairro pode ser a maneira catalisadora de ir transformando gradualmente a qualidade urbana. Hoje, com mais de $84 \%$ da população sendo urbana (de acordo com o censo do IBGE 2010), é urgente pensar em formas benéficas para morar nas cidades, de modo a combater os vários problemas vivenciados, entre eles, segregação socioespacial, moradias precárias, aumento do tráfego de veículos, poluição sonora e do ar, acidentes com mortes no trânsito, elitização espacial, desertificação das calçadas e insegurança.

Além destes, há outro tema que vem ganhando destaque na problemática das cidades brasileiras: a violência urbana. Ainda que se entenda que tais origens advêm da desigualdade social e da falta de oportunidades decorrentes da má distribuição de renda, das ineficientes políticas públicas nas áreas de educação, esporte, cultura, lazer, trabalho, especialistas argumentam que segurança pública e desenho das cidades são faces de uma mesma dimensão urbana, podendo o espaço ser um agente potencialmente amplificador destes transtornos. Portanto, o desenho do tecido urbano que estabelece a relação entre espaço público (vias, praças, parques e áreas livres) e espaço privado (moradias, instituições, comércios e serviços) pode definir a qualidade da vida urbana, sobretudo na indução ou não de pessoas nos espaços públicos.

Neste sentido, Jan Gehl coloca que:

O rumo dos acontecimentos não só reduziu as oportunidades para o pedestrianismo como forma de locomoção, mas também deixou sitiadas as funções cultural e social do espaço da cidade. A tradicional função do espaço da cidade como local de encontro e fórum social para os moradores foi reduzida, ameaçada ou progressivamente descartada (GEHL, 2013, p.3).

Por outro lado, a quadra, o edifício e o pedestre possuem íntima relação na dinâmica urbana. Vinícius Netto, em seu artigo a respeito do efeito da arquitetura nos espaços urbanos ${ }^{1}$ afirma que a configuração da quadra, o uso dado ao térreo do edifício e os tipos de usos que estão ali abrigados interferem diretamente 
na sensação de segurança transmitida para o pedestre que trafega na rua. Os "olhos vigilantes" (termo também adotado por Jane Jacobs como "os olhos da rua") e o tráfego contínuo gerado pela presença de atividades abrigadas no pavimento térreo, como comércio e serviços, contribuem para a efetividade desta vigilância mútua. Neste contexto,

(...) pedestres, ao utilizarem os espaços das ruas, aumentam a 'vigilância mútua' - isto é, um pedestre 'vigia' inconscientemente o outro, para sua própria segurança, e ao fazer isso aumenta o grau de controle sobre o espaço, o que beneficia a todos. De fato, pesquisas mostram que crimes violentos tendem a ocorrer longe dos olhos das pessoas. Aqui, o estranho não é o 'inimigo' como pensamos: ruas movimentadas são a melhor defesa contra o crime (NETTO, 2006, sp).

Todavia, na contramão desta vertente, o mercado imobiliário massifica a produção de tipologias habitacionais verticalizadas e isoladas, com pouca qualidade urbana, e quase sempre guiado pela máxima lucratividade e tratamento hostil ao pedestre. As soluções projetuais adotadas, em geral, se resumem a um espaço térreo privado, munido de grades, muros de grande altura, espaços residuais nos recuos e rígido controle de acesso na tentativa de "responder aos anseios de classes média e alta por mais segurança mas que termina por gerar exatamente o efeito oposto" (1). Embora cada objeto arquitetônico possua características próprias em função do seu uso, linguagem arquitetônica, decisões projetuais e padrão construtivo, a implantação do lote na quadra é sempre norteada por variáveis expressas na legislação urbanística de cada município e focando predominantemente o lote isolado: recuos, índices urbanísticos, quantidade de vagas de estacionamento em função das unidades habitacionais, dos comércios e da área construída, do solo permeável, do gabarito, dos acessos, dentre outros. Não se avaliam as implicações de modelo de uso e ocupação do solo na vida e nos espaços públicos em função da quadra.

Sem uma compreensão e uma mudança de paradigmas a respeito, o efeito negativo gerado por cada edificação no lote vai sendo gradativamente amplificado para a quadra, passando para a escala do bairro e, por fim, para a cidade. Além do mais, a legislação obsoleta, mais a conivência do poder público e a força do mercado imobiliário no contexto capitalista não contribui para uma mudança desse quadro, pelo contrário, acentua a segregação, o isolamento e a sensação de insegurança, prioritariamente nas calçadas. "A calçada deve ter usuários transitando ininterruptamente, tanto para aumentar na rua o número de olhos atentos quanto para induzir um número suficiente de pessoas de dentro dos edifícios da rua a observar as calçadas"2

\title{
2 CONTEXTUALIZAÇÃO - A DIMENSÃO HUMANA E A ESCALA DO BAIRRO
}

É cabível considerar que a reformulação da dimensão humana nas cidades perpassa pela escala dos bairros, desde que sua abordagem seja para favorecer a qualidade urbana. Em contraponto a mercantilização do solo, a dominação capitalista na produção da cidade e a invasiva presença do automóvel na ocupação dos espaços, com reflexos nocivos nos espaços públicos, bairros devem ser desenhados a partir dos aspectos atrativos para caminhadas e interações sociais. Neste sentido, o desenho urbano do bairro, suas quadras, a forma como as fachadas térreas dos edifícios se relacionam com as calçadas, o uso e a ocupação do solo, a densidade, as áreas verdes, a segurança influenciam na dimensão humana e nos padrões de urbanidade ${ }^{3}$ destes.

\begin{abstract}
O modo como as diferentes regiões de uma cidade são desenhadas afeta a percepção de segurança, os níveis de sociabilidade e o quanto as pessoas caminham - por motivos de lazer ou como meio de locomoção. Quanto mais conectado e dotado de áreas verdes for um bairro, maiores tendem a ser os índices de caminhabilidade e, consequentemente, de atividade física e sensação de bem-estar. O mais antigo e democrático dos meios de transporte floresce em ambientes densos, caracterizados pela mescla de usos residencial e comercial, com fachadas ativas e espaços de convívio que criam destinos para os trajetos a pé. São bairros projetados na escala dos pedestres, com calçadas acessíveis, mobiliário urbano, boa iluminação e espaços agradáveis. Se as pessoas caminham mais - e, assim, passam mais tempo na rua -, a tendência é que o bairro também se torne mais seguro. Isso porque as pessoas tendem a se afastar, de forma intuitiva, de lugares vazios. A presença de "outros", mesmo que desconhecidos, acaba com o vazio das ruas, tornando-as mais seguras e vivas 4 .
\end{abstract}

A cidade viva, segura e saudável, segundo Jan Gehl, pode ser exercida na pequena escala, nas quadras que incentivem experiências de interações sociais no dia a dia. Estratégias espaciais podem ser induzidas, com real atenção nos térreos associados aos espaços públicos, devidamente equilibrados na morfologia da quadra e nos seus usos. 
Por essa razão, é particularmente importante a qualidade das fachadas no andar térreo, perto das quais passamos, ao nível dos olhos, para aprimorar a sustentabilidade ambiental, enriquecer a qualidade de vida e promover equidade e inclusão social. Instrumentos e regulamentos para fortalecer a relação entre o andar térreo e a rua melhorarão a interação entre os espaços privados, semi-privados, semi-públicos e públicos. Espaços públicos atraentes e redes de ruas bem conectadas estimulam mais pessoas a caminhar e pedalar. (...) Desenhando prédios, construindo fachadas e espaços públicos, a atenção deve ser centrada não apenas no próprio espaço, mas na interação entre forma, função e conectividade entre os prédios, a rua e os espaços públicos. (KARSSENBERG et al, 2015)

Logo, sabemos que a dimensão humana nos bairros perpassa pelo desenho das quadras e de suas ruas, podendo ser convidativas conforme princípios da cidade compacta que estimulem o pedestrianismo e acessos a bens e serviços a pequenas distâncias, estimulando inclusive a economia local e as relações de vizinhança.

É preciso combater o urbanismo capitalista da especulação imobiliária na produção da cidade, mostrando à sociedade outras alternativas de morar que possam recuperar a verdadeira essência de viver nas cidades. $\mathrm{Na}$ era digital e da globalização, apesar de muitos avanços tecnológicos e da informação, acentua-se os contrastes nas relações humanas citadinas, reforçados pela cultura do individualismo e do abandono aos espaços públicos. Famílias e valores estão sendo moldadas pelo isolamento na forma de morar. Inúmeros condomínios fechados estão sendo construídos (horizontais ou verticais) nos subúrbios ou em bairros inseridos na malha urbana, "justificados" pela segurança privada. Espaço kids, academia, área verde e de lazer privados fazem parte do "arsenal" de oferta que imobiliárias apresentam, com intensa divulgação nos meios de comunicação para convencer os futuros usuários a essa maneira de morar segregada, e estão, lamentavelmente, conseguindo.

O crescente fenômeno de desvalorização dos espaços públicos urbanos é consequência, principalmente, da segregação espacial, causada justamente pelo complexo de redes de vigilância eletrônica e pelos muros altos e cegos que separam os lotes privados dos espaços públicos adjacentes (NÓBREGA, 2014).

Bairros inteiros estão sendo reformados ou construídos nessa ótica hermética, monofuncional e de baixa qualidade urbana. É necessário vivenciar a cidade ao invés de produzir espaços cegamente. A UN-Habitat vem disseminando nos países desenvolvidos e em desenvolvimento lições inspiradores para 0 desenvolvimento urbano, reconhecendo na organização e conectividade dos espaços públicos, nas ruas para as pessoas e não para os carros, e na multifuncionalidade dos bairros como fundamentais para atingir a qualidade de vida nas cidades. Nesta abordagem, os plinths (termo que designa o andar térreo dos edifícios) tem papel estratégico:

Hoje em dia, no planejamento de uma cidade, muitas vezes a interação e a
multifuncionalidade entre ruas, espaços públicos e as fachadas dos prédios no andar térreo
(os plinths) foram ignorados e negligenciados. Geralmente, as ruas são vistas apenas como
as ligações numa rede de ruas, possibilitando deslocamentos, e isso muitas vezes acabou
definindo como as ruas são usadas. Onde o espaço público é inadequado, mal desenhado,
ou privatizado, a cidade se torna cada vez mais segregada. Onde o andar térreo de um
prédio e a sua relação com a rua e o espaço público são ignorados, o seu uso e desenho
fazem com que o espaço seja pouco atraente e, às vezes, inseguro (KARSSENBERG,
2015).

A cidade ao nível dos olhos tem estreita relação com o desenho das quadras, porque a vida citadina deve ocorrer mais intensamente no chão. As tipologias dos edifícios inseridos nos lotes isolados alheios aos espaços públicos não são capazes de proporcionar desenvolvimento urbano. A cidade não é somente um entorno funcional, mas também um entorno de experiência. (...) Plinths são cruciais para a experiência e atratividade do espaço urbano, seja em áreas residenciais ou comerciais ${ }^{5}$.

Plinths incrementam a diversidade de usos nas quadras compatíveis com novas centralidades e conforme princípios da cidade compacta favorável às pequenas distâncias. Essas estratégias são relativamente simples de serem implementadas pela gestão urbana, desde que se tenha vontade política, continuidade nas políticas públicas e bons projetos urbanos. Densidade e quadras urbanas compactas devem ser associadas ao desenho urbano, e são prerrogativas projetuais, fazem parte do pensar o urbano a partir do projeto (com preocupação nas preexistências sócioespaciais), mas representa uma intenção técnica, é uma expertise. $O$ enfretamento para se redesenhar as quadras mais densas e compactas visa também não estimular outras construções nas periferias das cidades, não incentivar o espraiamento urbano.

Cidades sustentáveis são, necessariamente, compactas e densas. Como se sabe, maiores densidades urbanas representam menor consumo de energia per capita. Em contraponto ao modelo "Beleza Americana" de subúrbios espraiados no território com baixíssima 
densidade, as cidades mais densas da Europa e da Ásia são hoje modelos na importante competição internacional entre as global green ciities, justamente pelas suas altas densidades, otimizando as infraestruturas urbanas e propiciando ambientes de maior qualidade de vida pela sobreposição de usos (LEITE, 2012, p.13.).

Diante das abordagens acerca da quadra, bairro e cidade, entende-se, portanto, que o profissional arquiteto e urbanista tem a atribuição em contribuir com o desenho espacial nos bairros. Por outro lado, o mercado imobiliário vem influenciando no controle da expansão da cidade e nos destinos das alterações espaciais dos bairros, algo preocupante na medida em que é feito sem planejamento e sem noções de urbanidade. João Sette Whitaker coloca:

\begin{abstract}
A arquitetura que impera é a da extrema verticalização capitaneada pelo mercado imobiliário, a transfigurar sem culpa bairros tradicionais, produzindo prédios isolados no lote, cercados e murados, que renegam a rua e a cidade. A opção desenfreada pelo modelo do automóvel em detrimento de sistemas de transporte coletivos - que a arquitetura endossa alegremente - alimenta a oferta generalizada de unidades habitacionais com às vezes mais de dez vagas de garagem (!), o que leva à impermeabilização total do solo, afetando sem parcimônia a drenagem urbana e o escoamento de águas. [...] A lógica de construir condomínios murados com equipamentos de lazer e até comércio, ao invés de se abrir para a cidade, produz uma malha urbana segmentada, pouco fluida, e que vai aos poucos aniquilando a possibilidade de espaços públicos de qualidade (WHITAKER, 2011, sp.).
\end{abstract}

Já na história recente das grandes cidades brasileiras, muitos bairros foram construídos desde os anos 1970 conforme os paradigmas massificados da época do Sistema Financeiro da Habitação-SFH (principal órgão estatal financiador de moradias para funcionários públicos) e, atualmente, depois de mais de 30 anos, obras financiadas pelo programa do Governo Federal, Minha Casa Minha Vida ainda produzem conjuntos habitacionais impessoais e com baixa qualidade arquitetônica e urbanística, sem pluralidade de usos, com áreas de lazer subdimensionadas e sem espaços públicos qualificados, algo que implica em insatisfação dos usuários e descaracterização do conjunto edificado logo após a entrega das unidades.

Será que estamos reféns desta forma de morar ou existem outras espacialidades possíveis para alcançar melhor habitabilidade na cidade contemporânea? Como demonstrado, a resposta é que sim, há outras maneiras de se viver na cidade de forma mais humana, atraente e saudável, mas é preciso reconhecer que o problema não é só de redesenho, requalificação, ou de reforma nos tecidos bairros, é uma condição de legislação urbanística que corresponda e valide legalmente o melhor desenho espacial para as pessoas:

O poder público planeja a cidade através das normativas urbanas. É indispensável que elas sejam cidadãs e uma das estratégias é compreender o pavimento térreo como um prolongamento de toda a cidade. É um modo de conceber que reflete uma mudança na forma atual de ocupar os espaços públicos e privados (NÓBREGA, 2014, p.18).

\title{
O Plano Diretor Estratégico de São Paulo - PDE-SP
}

Uma experiência que merece reconhecimento na atualidade é o Plano Diretor Estratégico de São Paulo. Na capital paulistana, foi compreendido que a necessidade de mudança não só na escala da quadra mas também no âmbito da cidade, perpassa pelas legislações revisadas para serem aplicadas pelo poder executivo. O PDE-SP, Lei no 16.050, de 31 de julho de 2014, contempla uma ampla seleção de estratégias e diretrizes na busca pelo ordenamento da transformação da cidade. Dentre muitos aspectos, os presentes no documento, vale menção a determinados mecanismos que pode trazer melhor qualidade urbana, entre os quais o uso misto nos eixos de estruturação da transformação urbana:

\section{Como utilizar listas}

- Incentivo às fachadas ativas e ao uso misto. Isto ajuda a aumentar a vitalidade da rua e dos edifícios, sobretudo em bairros mais adensados de centros antigos, além de diminuir as distâncias percorridas pelo morador, permitindo que muitos percursos possam ser feitos a pé;

- Estímulo à criação de parques urbanos e áreas verdes;

- Diversas estratégias de mobilidade urbana com prioridade ao transporte público, desde melhorias nas redes de transporte coletivo de alta e média capacidade, intermodalidade, estímulo ao uso de transporte não motorizado através da expansão e melhoria das vias, ciclovias e ciclo faixas. Além disto, promove o desincentivo para vagas de garagem e cria limitadores para o número máximo de vagas de acordo com o uso de cada edifício. 
Figura 1: Uso misto nas edificações e térreo com o uso não residencial.

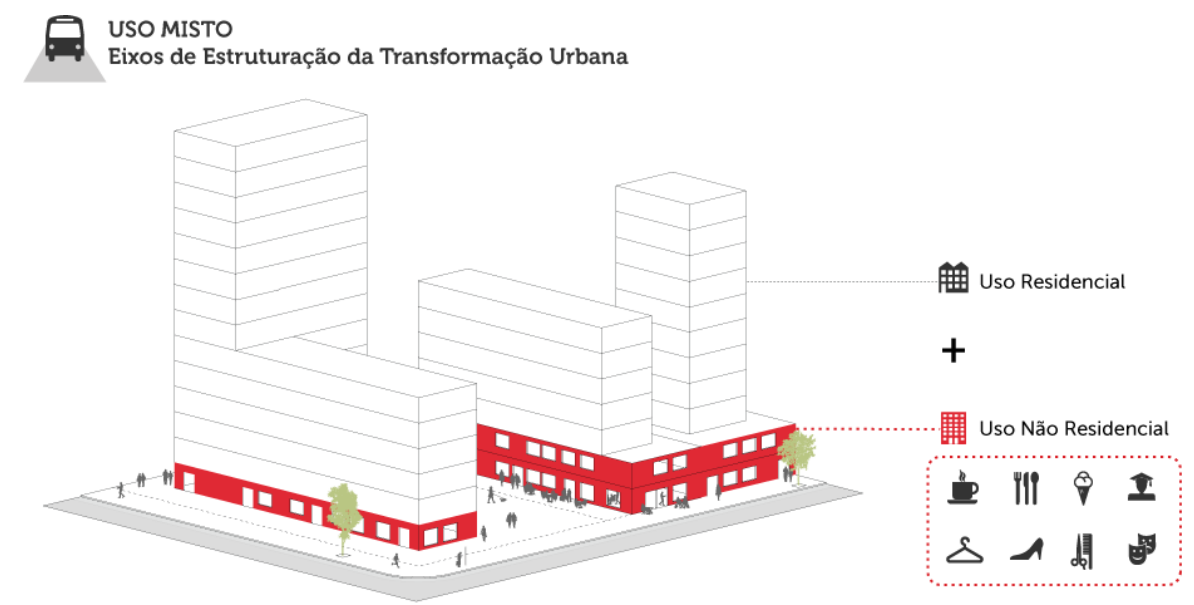

Fonte: Prefeitura de São Paulo (Disponível em http://gestaourbana.prefeitura.sp.gov.br/incentivo-ao-uso-misto/)

É notável que o PDE-SP adota medidas espaciais que irão repercutir diretamente no cotidiano das pessoas. Fachadas ativas, diversidade de usos, adensamento multifuncional, otimização do solo e da infraestrutura, incentivo ao pedestrianismo, aos transportes coletivos e não poluentes (bicicletas), fruição urbana são as vantagens dessas medidas. Nesse sentido, iniciar a mudança de desenho urbano pela quadra pode ser estratégico para revisão da legislação e para a requalificação urbana dos bairros. Já motivados pelo PDE vários são os exemplos de edifícios residenciais em São Paulo que possuem comércio no térreo e nos jardins frontais as calçadas que propiciam o prazer de vivenciar a cidade.

Figura 2: Ilustração de Juliana Russo que exemplifica os empreendimentos de São Paulo como consequência do novo PDE-SP. Comércios e jardins no térreo e interação direta entre o público e o privado. A direita, o Tetrys Pompeia do escritório FGMF arquitetos, edifício residencial na zona oeste da capital paulista.

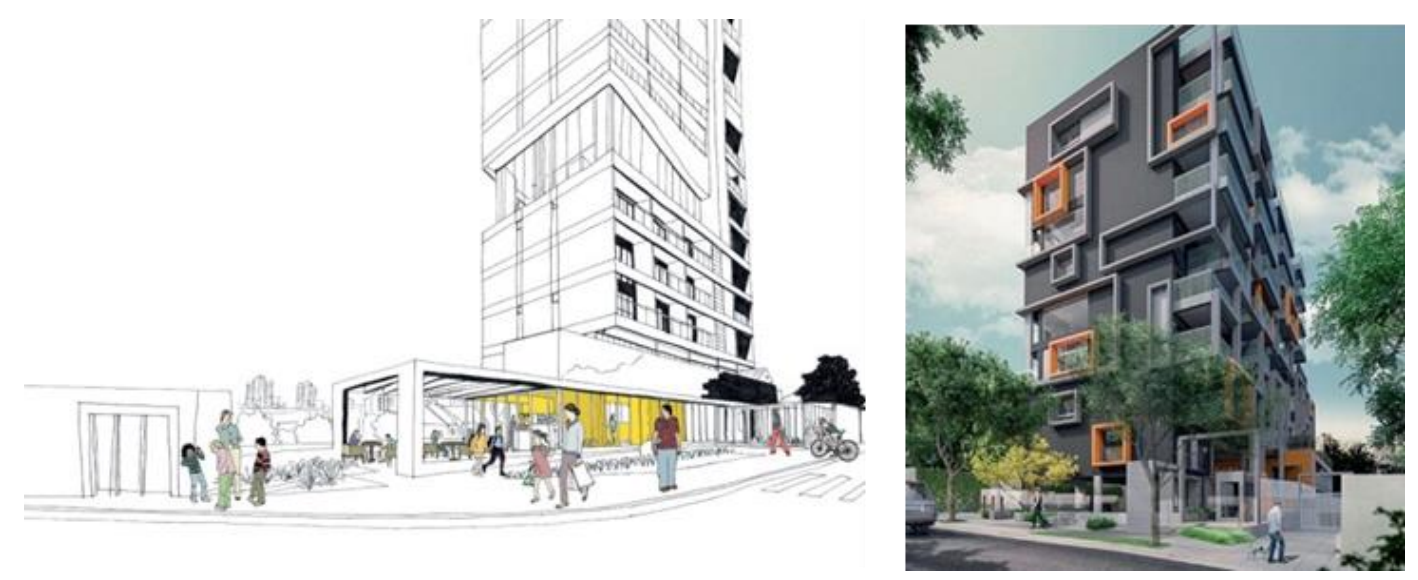

Fonte: Casa Abril (Disponível em http://casa.abril.com.br/casas-apartamentos/edificios-residenciais-em-sp-ganham-jardim-e-comerciono-terreo/)

Segundo os autores do Tetrys Pompeia, "um jardim rebaixado contíguo permite o contato dos pedestres com os topos de árvores enquanto o espelho d'água serve de singela transição entre o público e o privado. As pessoas de fora veem e entendem o térreo do edifício como parte de sua cidade" (FGMF arquitetos, 2014).

\section{Quadro de boas práticas urbanas}

No urbanismo contemporâneo, é possível encontrar alguns bons exemplos de concepções espaciais que combinam arquitetura e urbanismo de forma equilibrada. Os projetos contidos no quadro a seguir demonstram, sinteticamente, estratégias que buscam valorizar os espaços públicos, as fachadas ativas (através da pluralidade de usos), a mobilidade urbana e estimular as trocas sociais. 


\begin{tabular}{|c|c|c|}
\hline Imagem & Projeto & Descrição \\
\hline $\mid \begin{array}{lll}0 & 0 & 0 \\
0 & 0 & 0\end{array}$ & $\begin{array}{l}\text { Supermanzanas, } \\
\text { Barcelona } \\
\text { Espanha, } 2016\end{array}$ & $\begin{array}{l}\text { A prefeitura de Barcelona através do } \\
\text { plano de mobilidade urbana tem como } \\
\text { objetivo aumentar a caminhada e o uso } \\
\text { de bicicletas com ideais de segurança, } \\
\text { sustentabilidade, igualdade e eficiência. } \\
\text { O projeto eliminou alguns } \\
\text { estacionamentos, reduziu o limite de } \\
\text { velocidade para } 10 \mathrm{~km} / \mathrm{h} \text { nas áreas } \\
\text { próximas aos espaços peatonais, e } \\
\text { desviou o fluxo de veículos para as } \\
\text { bordas, liberando o centro para } \\
\text { pedestres e ciclistas. No interior da } \\
\text { superquadra, os únicos veículos } \\
\text { permitidos são os de emergência, os } \\
\text { dos moradores e os de carga. }{ }^{6}\end{array}$ \\
\hline & $\begin{array}{l}\text { Projeto } \quad \text { Bairro } \\
\text { Novo, São Paulo - } \\
\text { São Paulo, } 2004\end{array}$ & $\begin{array}{l}\text { Trata-se do vencedor do concurso } \\
\text { oferecido pela Prefeitura do Município } \\
\text { de São Paulo, através da Empresa } \\
\text { Municipal de Urbanização - EMURB, } \\
\text { "Bairro Novo - Concurso Nacional para } \\
\text { um Projeto Urbano". O projeto se inspira } \\
\text { no plano urbanístico de Barcelona de } \\
\text { Idelfonso Cerdá (1859), trazendo as } \\
\text { esquinas chanfradas como coringas de } \\
\text { usos comerciais e prédios com até seis } \\
\text { pavimentos, respeitando assim a escala } \\
\text { humana, além das praças entre as } \\
\text { edificações. }\end{array}$ \\
\hline & $\begin{array}{l}\text { Bairro Cidade } \\
\text { Universitário Pedra } \\
\text { Branca, município } \\
\text { Palhoça, região } \\
\text { metropolitana de } \\
\text { Florianópolis - } \\
\text { Santa Catarina. } \\
1990\end{array}$ & $\begin{array}{l}\text { O projeto incorpora critérios espaciais } \\
\text { para aproximar moradias, comércio, } \\
\text { serviços, lazer, trabalho e educação a } \\
\text { serem acessadas em curtas distâncias. } \\
\text { É um projeto que parte da iniciativa } \\
\text { pública e privada, tendo como } \\
\text { inspiração um novo urbanismo mais } \\
\text { comprometido com sustentabilidade e } \\
\text { mais associado à vida ao ar livre, aos } \\
\text { passeios a pé ou de bicicleta e à } \\
\text { convivência cidadã. }\end{array}$ \\
\hline
\end{tabular}

\section{As transformações urbanas pela quadra convencional - Impactos negativos}

Vários bairros estão passando por transformações urbanas devido ao adensamento e à verticalização sem planejamento, independentemente de sua faixa de renda. Sem avaliar os impactos, se pensa apenas no lote isolado, no lucro e no valor econômico para incorporadores imobiliários. Não se considera o cotidiano das pessoas no âmbito da habitabilidade plena. Deveriam investigar possibilidades espaciais tentando conciliar densidade ótima, diversidade de usos e pedestrianismo, a partir do conceito de bairro-cidade ou quadra-cidade. 
Figura 3: Três lotes remembrados no bairro de Manaíra em João Pessoa - PB. O bairro possui um dos metros quadrados mais caros da cidade, com processo segregado de verticalização já avançado. A direita, separação física entre o público e o privado por portões de garagens, e quadra adensada sem planejamento, no bairro dos Bancários, Rua Esmeraldo Gomes Vieira.
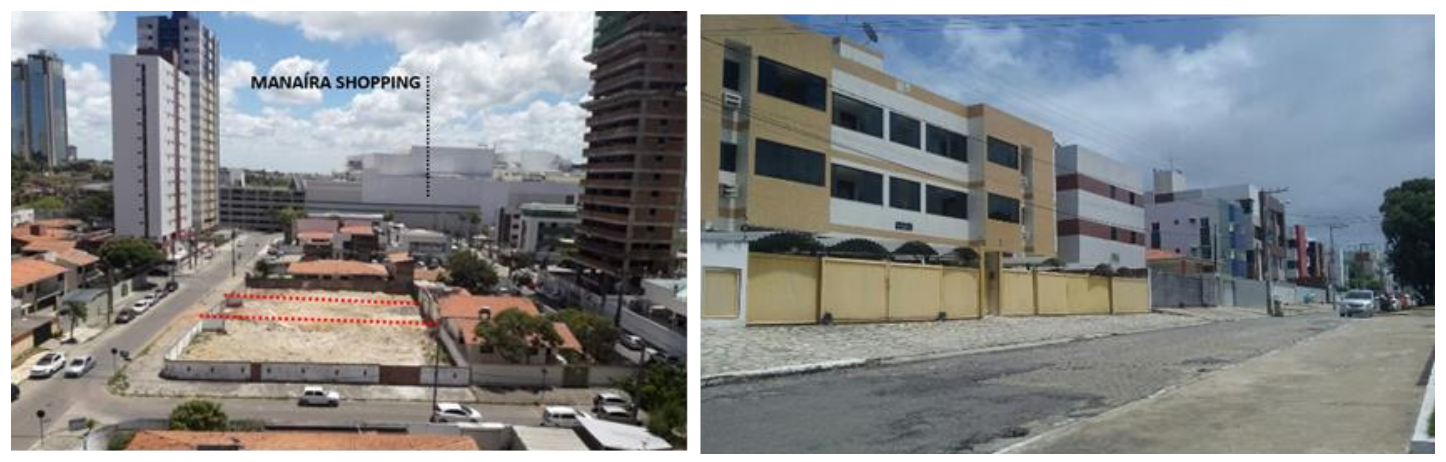

Fonte: Acervo pessoal do autor, 2016

É comum constatar nos casos negativos, que as tipologias de casas e edifícios multifamiliares adotem os muros "cegos" que separam fisicamente o público do privado. Isto resulta inevitavelmente em calçadas mais desertas, com pouco movimento de pedestres, que causam sensação de insegurança justamente pela ausência dos "olhos da rua"2. Quando observado da escala da quadra, os lotes fechados com fachadas inativas e uniformidade de usos, sobretudo o residencial, dificultam o contato social e a provisão das necessidades diárias de comércio e serviços.

Tal carência de pluralidade de usos pode ser observada na figura 4 do Bairro de Mangabeira (quadra de intervenção propositiva), onde residências são modificadas para abrigar comércios a fim de atender as demandas cotidianas. Caso houvesse previsão de combinação de usos no arranjo espacial da quadra, este tipo de improviso não ocorreria. A Rua Joamir Severino Santos no mesmo bairro possui lotes fechados por muros e "puxadinhos" no recuo frontal que descaracterizou o conjunto urbano. O que se prevalece quando se está caminhando por ruas com essas características é a sensação de estar em uma cidade "fantasma", sem pessoas, sem vida, mesmo com os improvisados e poucos comércios verificados.

Figura 4: Moradias são descaracterizadas (improvisadamente) para abrigar atividade comercial do morador. Rua Joamir Severino Santos no bairro de Mangabeira.
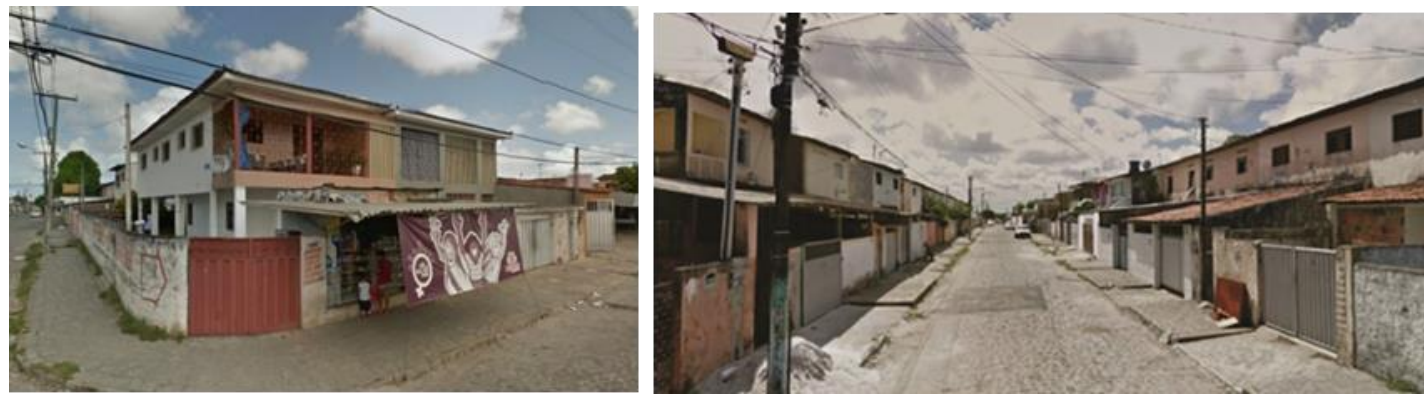

Fonte: Acervo pessoal do autor, 2016

Figura 5: Paisagens e dinâmicas urbanas transformadas pelo processo de verticalização nos bairros de classe média Altiplano e Bancários. Térreos que negam as calçadas, ruas sem vigilância social, e ausência de vegetação.
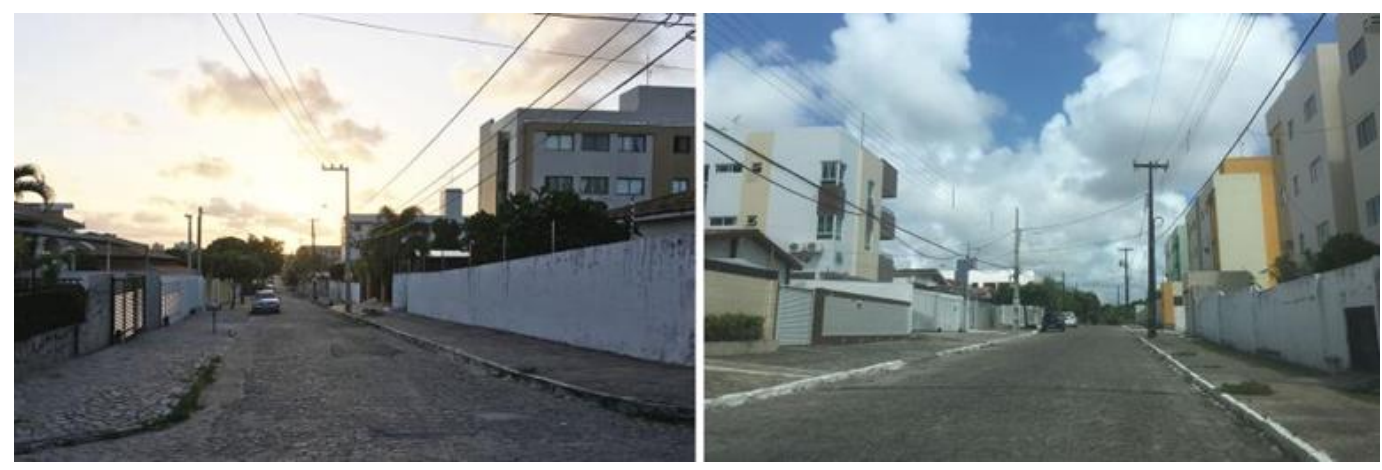

Fonte: Acervo pessoal do autor, 2016 


\section{A investigação propositiva}

O estudo "piloto-investigativo" de uma quadra em bairro de baixa renda na zona sul da cidade de João Pessoa-PB, Mangabeira, reconhece que a quadra urbana interfere na relação dos espaços públicos e privados, na vida das pessoas, na mobilidade urbana, na economia local, merecendo cuidado especial no planejamento urbano. Para promover então uma escala mais humana nos bairros, é proposto eliminar as barreiras físicas (muros, cercas, grades), e prever a polifuncionalidade de atividades no térreo visando contribuir com as interações sócioespaciais cotidianas. Como mudança gradual, a proposta parte do remembramento de dois lotes de $10 \times 20 \mathrm{~m}$ (lotes típicos em bairros de baixa renda) como referência catalisadora de parcelamento alternativo do solo e da ordenação espacial.

Figura 6: Mapas de localização da quadra.
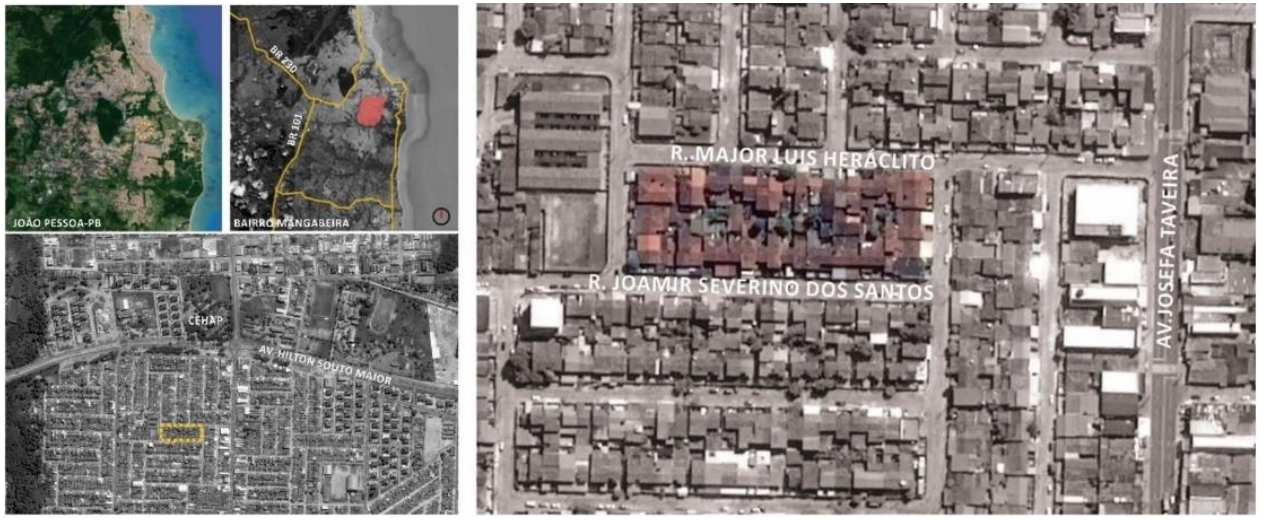

Fonte: Google Maps; Imagem trabalhada pelos autores, 2016.

Uma prática comum adotada pelos construtores na implantação de tipologia multifamiliar verticalizada é o remembramento de dois ou mais lotes, para atender à exigência legal da área mínima em conformidade com o Código de Urbanismo municipal, ou simplesmente prover uma construção de maior porte, com mais unidades habitacionais e oferta de equipamentos de uso privado do empreendimento. Esta modificação no parcelamento do solo traz reflexos diretos na quadra, pois gradativamente os bairros vão tomando outra conformação e outra dinâmica que impactam na vizinhança, na infraestrutura local, além da já mencionada segurança pública, fatos já ocorridos em João Pessoa nos bairros de todas as faixas de renda tais como Mangabeira, Manaíra e Bancários ${ }^{9}$, dentre outros. Outro aspecto nocivo, por exemplo, por não haver comércios e serviços próximos, pessoas ficam cada vez mais dependentes dos carros para atender suas necessidades do dia a dia. Casas são demolidas, dando lugar a edifícios de 04 pavimentos ou mais, com negação da rua e ausência de uso misto no térreo. A transformação é pontual, mas com repercussões no entorno e sem um planejamento dos impactos na quadra e na vida das pessoas, sobretudo pelo aumento da frota de veículos derivada das garagens geradas, com efeito nocivo capaz de acentuar os congestionamentos e o aumento de emissões de gases poluentes.

Figura 7: A matemática mercadológica do remembramento de lotes.

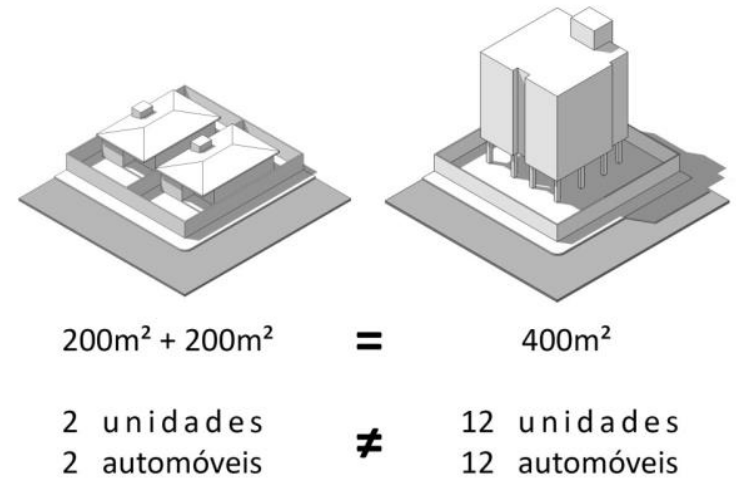

Fonte: Acervo pessoal dos autores, 2016

Como contraponto a essa realidade, a quadra aberta híbrida se mostra como uma alternativa ao habitar da quadra fechada, na medida em que promovem espaços de convivência mais democráticos, fachadas ativas no térreo, uso misto (residencial e comercial) para aproveitar a ocupação do solo, que juntos contribuem 
para a fruição urbana nos bairros. Na prática, para auxiliar também na efervescência da economia local, os térreos podem ter farmácias, padarias, mercadinhos, livrarias, cafés, bares, lanchonetes, restaurantes, correios, bancos eletrônicos, lojas de roupas, salão de beleza, chaveiros, bancas de revistas e demais usos conforme necessidade e vocação para cada caso.

Assim, para termos cidades mais humanas, é preciso ter bairros mais atraentes e seguros. Deste modo, o combate à sensação de insegurança perpassa, inclusive, por um redesenho da quadra, da sua oferta de usos aos moradores, repercutindo na movimentação de pessoas e na animação urbana dos bairros. A qualidade dos espaços públicos imprimindo o sentido da escala local, também deve ser considerada como elemento espacial estruturador no desenho das quadras. E isso pode ser possível sem grandes transtornos e a partir de uma intervenção urbana de pequena escala, contrária à forma especulativa, pontual e danosa da tipologia habitacional verticalizada isolada.

A priori, pode-se iniciar com o remembramento de dois lotes de 10x20m, típico do bairro estudado, com o pavimento térreo mais humanizado, integrado com a calçada. Na relação entre espaço privado e público, portões flexíveis, correntes móveis ou outras opções podem ser utilizadas no período noturno, resguardando a garagem do morador, mas sem prejuízo na integração com o espaço público, mesmo considerando, que a necessidade do automóvel pode ser revista conforme políticas públicas de mobilidade urbana mais eficientes, e com prioridade ao pedestrianismo e modais não poluentes. Outra alternativa do térreo é prever bancos demonstrando gentileza urbana, enquanto espaço de transição mais atraente entre o espaço público e o privado. Adotar o térreo parcialmente ou totalmente comercial, ou misto (comércio e habitação), vai depender de cada caso específico e características do tecido urbano como demonstrado em FILHO, 2003.

Figura 8: Remembramento de dois lotes e início da transformação na quadra. Na escala privada, a planta baixa térrea, demostra que a expansibilidade pode alcançar até 04 quartos, favorável ao planejamento familiar ao longo dos anos.
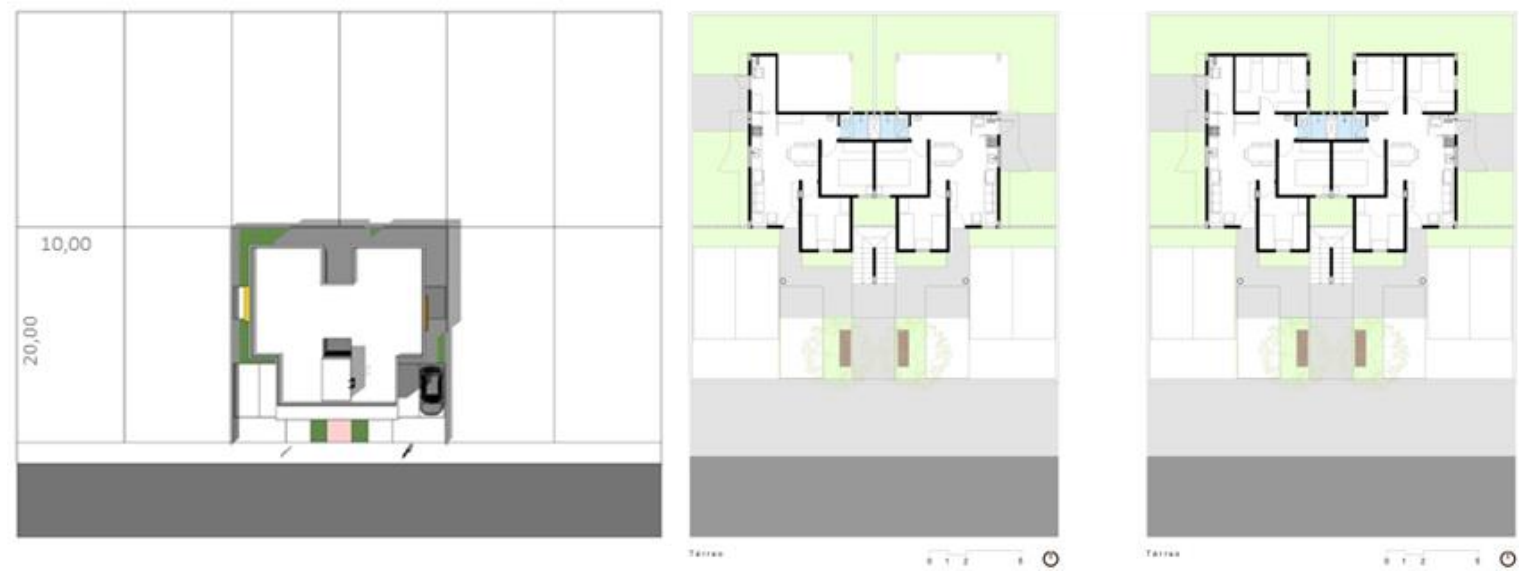

Fonte: Acervo pessoal dos autores, $2016^{10}$.

Figura 9: Simulação virtual do edifício em lote remembrado, demonstrando o térreo mais humanizado, inclusive com bancos sob árvores. À direita, simulação da tipologia térreo + 2 pavimentos e o edifício de uso misto na esquina.
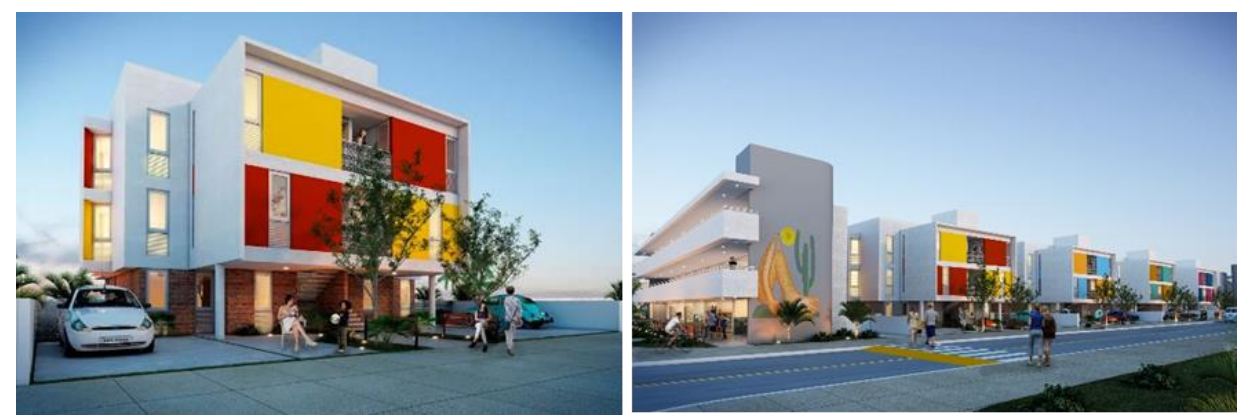

Fonte: Acervo pessoal dos autores, $2016^{10}$. 
Figura 10: Cenário de quadra híbrida - Situação Atual x Situação Proposta. Neste, o comércio e serviços aparecem no térreo e nos extremos da quadra, aliados ao uso residencial com 3 pavimentos. Previsão de marquises e arborização como elementos fundamentais para a proteção dos pedestres.

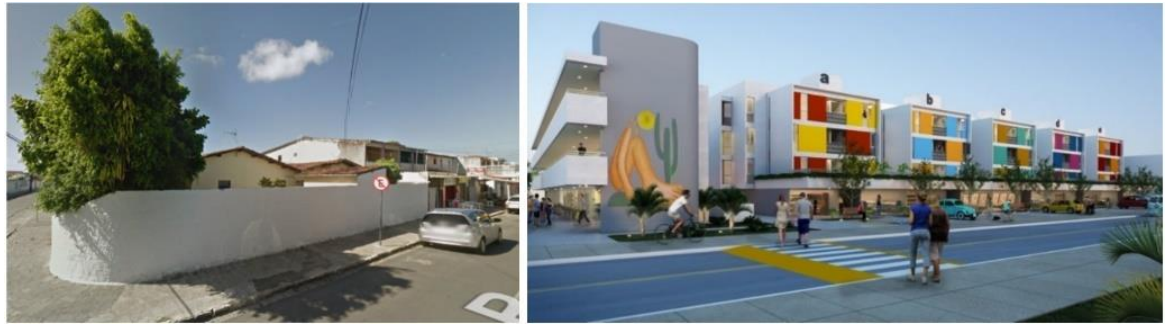

Fonte: Google StreeView, 2016; Acervo pessoal dos autores, $2016^{10}$.

Ainda neste contexto de requalificação, a mistura de funções no nível do térreo contribui, também, para a formação de comunidades mais vibrantes e com possibilidade de estimular o empreendedorismo no bairro na medida em que vários comércios e serviços podem ser disseminados, gerando renda, negócios e trocas de ideias.

Figura 11: A partir dos remembramentos, evolução das transformações graduais e planejadas na quadra, no espaço de tempo de oito anos (hipoteticamente). Edifício empresarial e comercial nos extremos, opção do comércio no térreo (cor amarelo), e via compartilhada no processo de requalificação espacial visando o controle veicular na quadra.
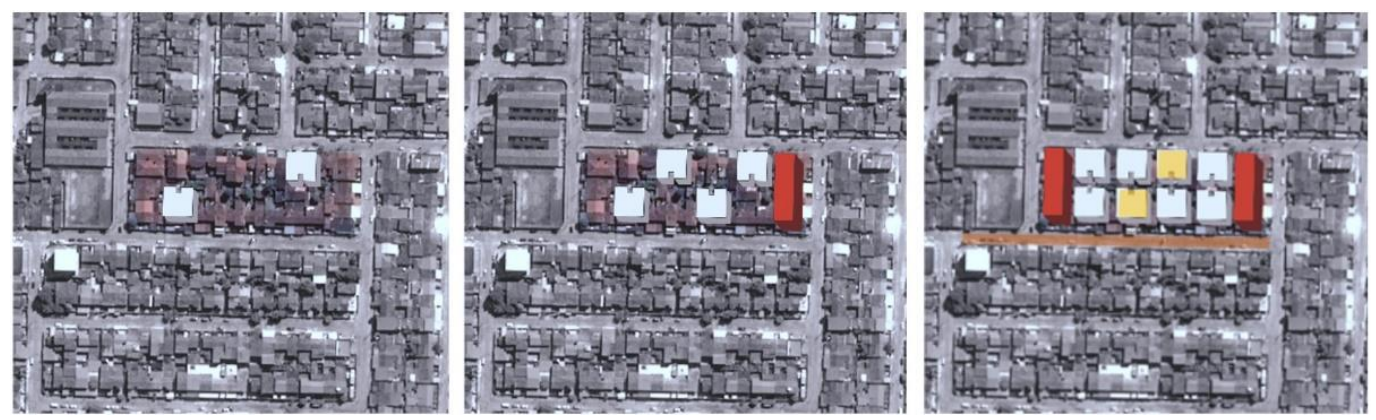

Fonte: Google Maps, 2016, Imagem trabalhada pelos autores, $2016^{10}$.

A figura 11 demonstra que as transformações na quadra podem ocorrer, ao longo dos anos, conforme a dinâmica do mercado imobiliário, mas conciliando viabilidade econômica com qualidade urbana. Tipologias variadas podem ser concebidas, desde que se mantenha o mesmo princípio de multifuncionalidade e pedestrianismo.

Portanto, o estudo materializado neste artigo evidencia a importância da relação mais integradora entre o edifício e a rua e aponta a verticalização e densidade planejadas como possível caminho viável nos bairros, seja através do remembramento gradual de tipologias mistas em quadras preexistentes, seja a partir de três cenários hipotéticos, mas associados aos desenhos concebidos desde a origem da intervenção da quadra híbrida aberta (ver concepções espaciais 01 a 03).

\section{Concepções espaciais propostas}

Entende-se que as concepções e as modificações de quadras completas podem causar diversos danos na esfera socioespacial quando construídas inadequadamente, como também é sabido que o mercado imobiliário muitas vezes não tem tal entendimento ou simplesmente não leva em consideração os impactos nocivos gerados pela segregação, construindo diversos condomínios fechados com a promessa de "segurança e liberdade" aos moradores. É notório que tais condomínios fechados negam a cidade, o que ocasionam ainda mais a cultura do individualismo se contraponto às trocas sociais proporcionadas pela cidade.

A cultura do medo disseminada, incentiva a incessante busca pela segurança e vê os altos muros, cercas elétricas e câmeras como únicas soluções para a violência, de modo a acreditar que essa é a única forma do habitar na urbe. Vivenciar a cidade, só se for apenas como passagem em vias expressas dentro de seus automóveis com ar-condicionado e vidros fechados. Nesse cenário nefasto, a importância do profissional arquiteto e urbanista é fundamental para demonstrar tecnicamente outro olhar sobre a organização espacial mais humanizada.

Figura 12: Condomínios fechados alheios à cidade. 

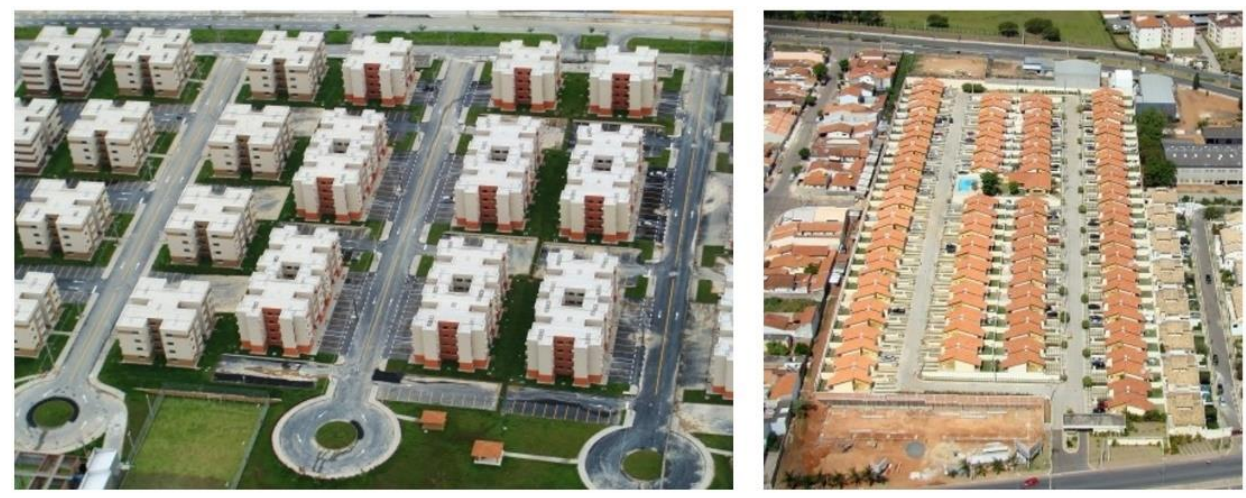

Fonte: Acervo LabQuapá - FAU-USP, apud WHITAKER, 2011. Disponível em: http://www.vitruvius.com.br/revistas/read/arquitextos/12.133/3950.

Figura 13: Concepção da Quadra Híbrida inserida no tecido urbano convencional como contraponto aos condomínios fechados. Facilidades urbanas acessíveis a curtas distâncias.

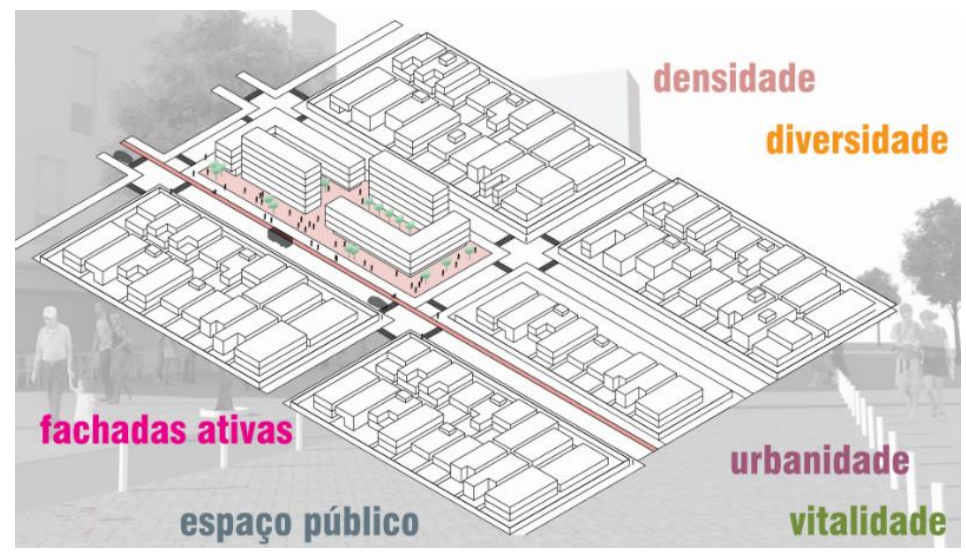

Fonte: Acervo pessoal dos autores, 2016.

Como contraponto ao contexto descrito, neste artigo propõe-se diversas concepções de quadras híbridas abertas que podem proporcionar qualidade de vida aos moradores e outro projeto de cidade. Importante mencionar, que todos demonstram não só a preocupação com a diversidade de usos na quadra, mas com fatores de proteção climática e conforto térmico como sendo fundamentais à permanência dos pedestres nos espaços públicos. Seguem os arranjos espaciais simulados esquematicamente, com destaque a eliminação dos muros nos limites das quadras (nos desenhos: branco habitação, vermelho comércio, amarelo empresarial e serviços), tendo a implantação dos edifícios os conformadores da relação entre o público e o privado.

\section{Quadro arranjos espaciais - cenários investigativos das quadras híbridas}

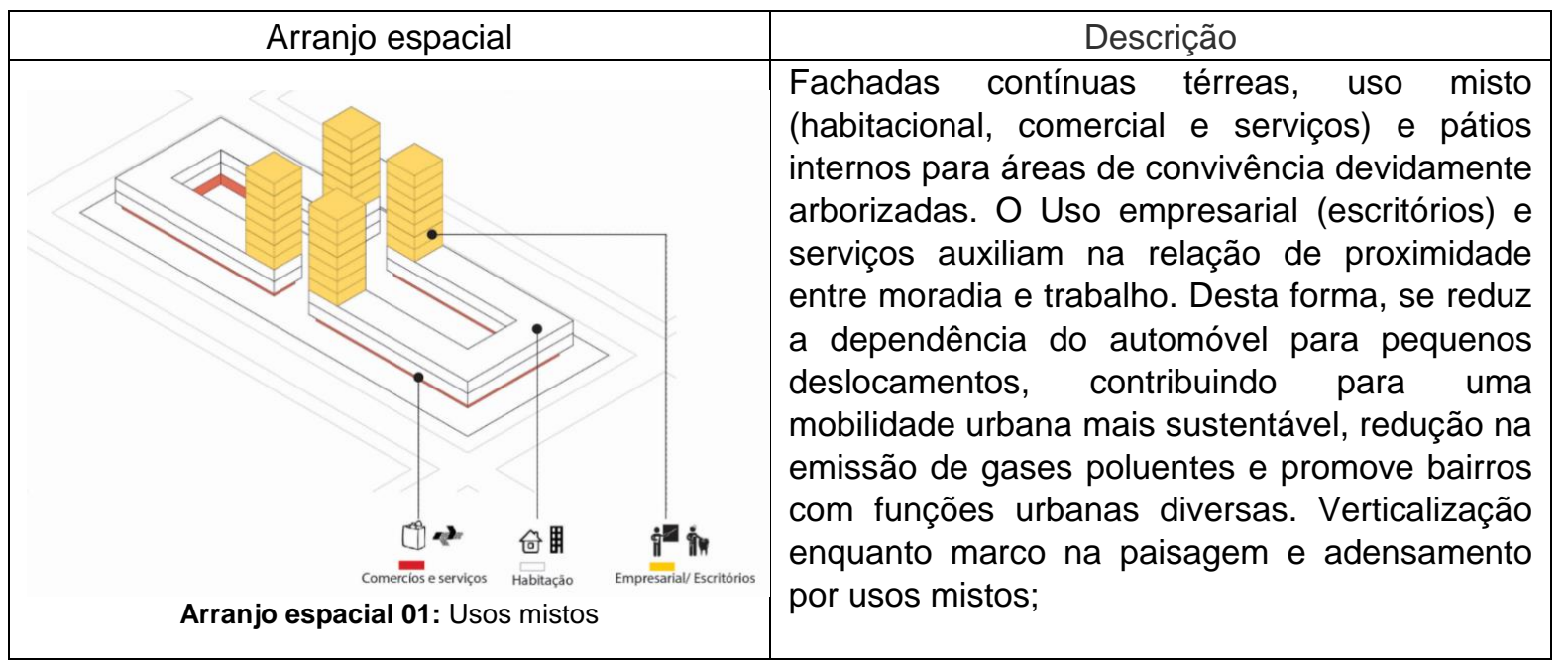




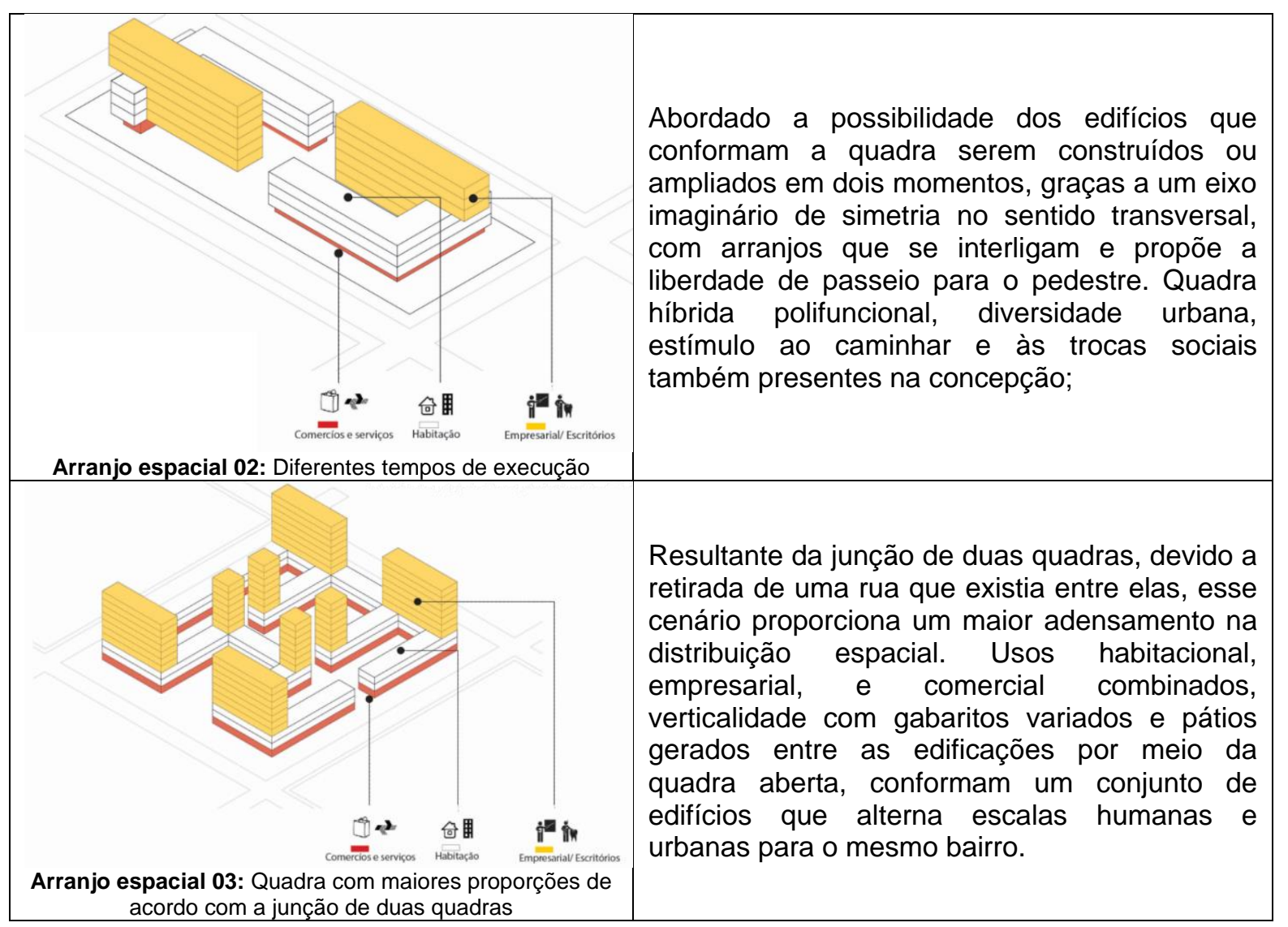

\section{CONSIDERAÇÕES FINAIS}

O artigo sugere que as mudanças nas quadras dos bairros sejam realizadas de forma gradual, considerando o desenho urbano enquanto instrumento fundamental para revisão da legislação urbanística e para a humanização dos espaços. Para ilustrar, e possivelmente sensibilizar os gestores e o setor privado, foram utilizadas investigações espaciais comparativas como ferramentas para demonstrar hipoteticamente uma alternativa ao que foi construído. Aponta que há outras formas de organização espacial combinando tipologias de uso misto (habitacional, comercial e serviços) com as necessidades diárias dos moradores, conforme conceitos de cidade compacta e centralidades urbanas. Os estudos mostrados não tem a pretensão de afirmar a melhor solução, mas são visíveis as discrepâncias entre os casos predominantes na cidade e os hipotéticos, embora que de forma esquemática.

As construções do espaço privado, que representam grande parcela do solo urbano, podem ser viabilizadas em harmonia com o espaço público, sendo mais atraentes para as trocas sociais e gentis para com a cidade. Por isso, é possível demonstrar que não é incompatível fazer operações urbanas entre agentes do mercado imobiliário e as noções do bom urbanismo. Danosos são as legislações inadequadas que provocam o "desenho das quadras fechadas" e gestores negligentes serem uns dos responsáveis pela cidade hostil e hermética. O fazer urbano mais humano, perpassa inevitavelmente pela mudança na legislação, e as simulações espaciais e os estudos comparativos aqui investigados podem auxiliar a aprofundar essa discussão.

Já a produção habitacional, sobretudo as de baixa e média renda, não pode ser vista de forma meramente "quantitativa" e especulativa, desvinculada da noção de cidade. Entende-se que, nesse processo, o térreo e suas fachadas ativas, de dia e de noite, tem papel essencial para a relação mais harmoniosa com os pedestres. Pessoas, espaço e aspectos legais fazem parte de um mesmo projeto de cidade de forma sistêmica. A simulação espacial pode, neste sentido, apoiar as discussões das revisões das legislações urbanísticas, começando pelas quadras dos bairros com consequências diretas no cotidiano das pessoas.

Portanto, medidas na legislação orquestrada pelo bom urbanismo podem resultar simultaneamente na boa arquitetura e na qualidade urbana, sobretudo na escala humana dos bairros. Por outro lado, legislações obsoletas, podem acentuar os danos no espaço citadino, a exemplo dos casos aqui mostrados no Bairro de Mangabeira da capital paraibana, semelhantes em várias cidades brasileiras. 


\section{REFERÊNCIAS}

FILHO, Candido Malta Campos. Reinvente seu bairro: caminhos para você participar do planejamento de sua cidade. São Paulo: Ed.34, 2003.

FGMF arquitetos. Revista Monolito 21. Editora Monolito, São Paulo, 2014.

GEHL, Jan. Cidades para Pessoas. São Paulo: Perspectiva, 2013.

IBGE (Brasil) (Comp.). Censo Demográfico. São Paulo: lbge, 2010. Disponível em: http://www.censo2010.ibge.gov.br/sinopse/index.php. Acesso em: 25 nov. 2016.

JACOBS, Jane. Morte e Vida das Grandes Cidades. 3. ed. São Paulo: Martins Fontes, 2011.

KARSSENBERG, Hans et al. A Cidade ao Nível dos Olhos: Lições para os plinths. Porto Alegre: EdiPUCRS, 2015.

LEITE, Carlos. Cidades sustentáveis cidades inteligentes, Desenvolvimento sustentável num planeta urbano. 2012.

NÓBREGA, Maria de Lourdes C.C. "Por um espaço público cidadão: o encontro do edifício com a rua". Recife: Publicações SENGE, 2014.

NETTO, Vinícius de Moraes. O efeito da arquitetura: impactos sociais, econômicos e ambientais de diferentes configurações de quarteirão. Arquitextos (São Paulo. Online), v. 079.07, 2006.

PACHECO, Priscila. The City Fix Brasil. Pessoas tendem a ser mais felizes e saudáveis em bairros caminháveis. Disponível em: http://thecityfixbrasil.com/2017/03/22/pessoas-tendem-a-ser-mais-felizes-e-saudaveis-em-bairroscaminhaveis/. Acesso em: 22 mar. 2017.

Prefeitura de São Paulo. Plano Diretor Estratégico de São Paulo. Disponível em: http://gestaourbana.prefeitura.sp.gov.br/. Acesso em 27 abr. 2017.

WHITAKER, João Sette. Perspectivas e desafios para o jovem arquiteto no Brasil. Qual o papel da profissão? Arquitextos, São Paulo, ano 12, n. 133.07, Vitruvius, jul. 2011. Disponível em: http://www.vitruvius.com.br/revistas/read/arquitextos/12.133/3950.

\section{NOTAS}

1 Vinícius Netto coloca: "A densidade arquitetônica e a presença abundante de térreos comerciais (algo que o mercado e a indústria da construção civil, sem saber das consequências, vêm eliminando) contribuem para intensidade de uso pedestre. [...] Pedestres, ao utilizarem os espaços das ruas, aumentam a 'vigilância mútua' - isto é, um pedestre 'vigia' inconscientemente o outro, para sua própria segurança, e ao fazer isso aumenta o grau de controle sobre o espaço, o que beneficia a todos. De fato, pesquisas mostram que crimes violentos tendem a ocorrer longe dos olhos das pessoas. Aqui, o estranho não é o 'inimigo' como pensamos: ruas movimentadas são a melhor defesa contra o crime”. NETTO, Vinícius de Moraes. O efeito da arquitetura: impactos sociais, econômicos e ambientais de diferentes configurações de quarteirão. Arquitextos (São Paulo. Online), v. 079.07, 2006.

2 JACOBS, Jane. Morte e vida de grandes cidades. São Paulo: Martins Fontes, 2011.

${ }^{3} \mathrm{O}$ conceito aqui de urbanidade se aproxima ao de Aguiar que se apoia nas definições de Jacobs sobre vitalidade e diversidade, e em Lynch sobre legibilidade, continuidade de espaços e a sinestésica do movimento no espaço urbano para entender que "a urbanidade estaria nesse modo de apropriação da situação pelas pessoas”. Aguiar, Douglas e Netto, Vinicius M. (Org.). Urbanidades, Rio de Janeiro: Folio Digital, Letra e Imagem, 2012, p.20.

${ }^{4}$ Pessoas tendem a ser mais felizes e saudáveis em bairros caminháveis. Disponível em:

http://thecityfixbrasil.com/2017/03/22/pessoas-tendem-a-ser-mais-felizes-e-saudaveis-em-bairros-caminhaveis/

${ }^{5}$ KARSSENBERG, Hans. A cidade ao nível dos olhos: lições para os plinths. Porto Alegre: EDIPUCRS, 2015.

${ }^{6}$ KARSSENBERG, Hans. A cidade ao nível dos olhos: lições para os plinths. Porto Alegre: EDIPUCRS, 2015.

${ }^{7}$ Concurso Bairro Novo, São Paulo, 2004 Portal Vitruvius. Disponível em:

http://www.vitruvius.com.br/revistas/read/projetos/04.044/2398?page=6

${ }^{8}$ Bairro Cidade Universitária Pedra Branca. Disponível em: http://cidadepedrabranca.com.br/um-pouco-de-historia/

${ }^{9}$ O Relatório de Indicadores Criminais no $1^{\circ}$ Quadrimestre de 2014 pela Secretaria de Segurança e Defesa Social (Seds) traz o ranking de bairros com maior incidência de Crimes Violentos contra o Patrimônio (CVPs), ou seja, roubo (exceto latrocínio) mediante grave ameaça de violência à pessoa. No topo da lista, estão: 1- Mangabeira com 161 ocorrências; 2- Centro, com 139; 3- Manaíra, com 120; 4- Bancários, com 102 e 5- Cristo Redentor, com 100 ocorrências no período. Vale lembrar que os indicadores não refletem totalmente a realidade, pois muitos dos casos não são relatados pela vítima e consequentemente não são registrados e apurados pelas Polícias Civil e Militar. Crimes desta natureza são reflexos diretos de ruas com menor vivacidade urbana.

10 Simulações virtuais da proposta (Figuras 10 e 11): Danilo Paiva. Auxílio no desenvolvimento gráfico das plantas baixas: Izabelly Gouveia.

NOTA DO EDITOR ( ${ }^{\star}$ ) O conteúdo do artigo e as imagens nele publicadas são de responsabilidade do(s) autor(es). 